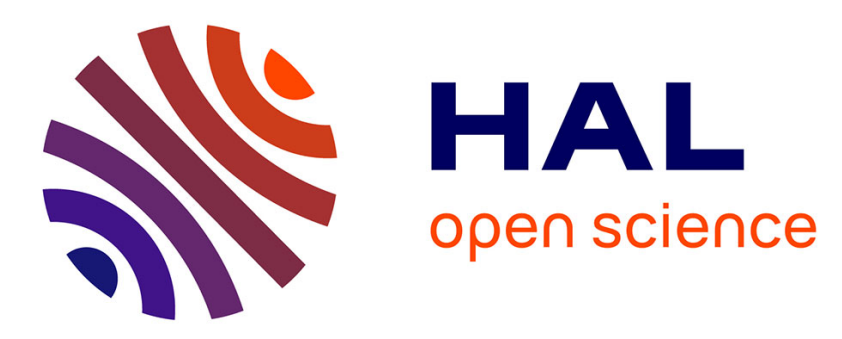

\title{
Phosphahelicenes: from chiroptical and photophysical properties to OLED applications
}

Keihann Yavari, Wylliam Delaunay, Nicolas de Rycke, Thibault Reynaldo, Paul Aillard, Monika Srebro-Hooper, Victoria Y. Chang, Gilles Muller, Denis Tondelier, Bernard Geffroy, et al.

\section{To cite this version:}

Keihann Yavari, Wylliam Delaunay, Nicolas de Rycke, Thibault Reynaldo, Paul Aillard, et al.. Phosphahelicenes: from chiroptical and photophysical properties to OLED applications. Chemistry - A European Journal, 2019, 25 (20), pp.5303-5310. 10.1002/chem.201806140 . hal-02010723

\section{HAL Id: hal-02010723 \\ https://hal.science/hal-02010723}

Submitted on 7 Feb 2019

HAL is a multi-disciplinary open access archive for the deposit and dissemination of scientific research documents, whether they are published or not. The documents may come from teaching and research institutions in France or abroad, or from public or private research centers.
L'archive ouverte pluridisciplinaire HAL, est destinée au dépôt et à la diffusion de documents scientifiques de niveau recherche, publiés ou non, émanant des établissements d'enseignement et de recherche français ou étrangers, des laboratoires publics ou privés. 


\section{CHEMISTRY A European Journal}

\section{Accepted Article}

Title: Phosphahelicenes: from chiroptical and photophysical properties to OLED applications

Authors: Jeanne Crassous, Wylliam Delaunay, Nicolas De Rycke, Thibault Reynaldo, Monika Srebro-Hooper, Gilles Muller, Denis Tondelier, Bernard Geffroy, Arnaud Voituriez, Angela Marinetti, Muriel Hissler, Keihann Yavari, and Paul Aillard

This manuscript has been accepted after peer review and appears as an Accepted Article online prior to editing, proofing, and formal publication of the final Version of Record (VoR). This work is currently citable by using the Digital Object Identifier (DOI) given below. The VoR will be published online in Early View as soon as possible and may be different to this Accepted Article as a result of editing. Readers should obtain the VoR from the journal website shown below when it is published to ensure accuracy of information. The authors are responsible for the content of this Accepted Article.

To be cited as: Chem. Eur. J. 10.1002/chem.201806140

Link to VoR: http://dx.doi.org/10.1002/chem.201806140 


\title{
Phosphahelicenes: from chiroptical and photophysical properties to OLED applications
}

\author{
Keihann Yavari, ${ }^{[\mathrm{b}]}$ Wylliam Delaunay, ${ }^{[\mathrm{a}]}$ Nicolas De Rycke,${ }^{[\mathrm{a}, \mathrm{c}]}$ Thibault Reynaldo, ${ }^{[\mathrm{a}]}$ Paul Aillard, ${ }^{[\mathrm{b}]}$ \\ Monika Srebro-Hooper, ${ }^{*[\mathrm{dd}]}$ Victoria Y. Chang, ${ }^{[\mathrm{e}]}$ Gilles Muller, ${ }^{[\mathrm{e}]}$ Denis Tondelier, ${ }^{\left[{ }^{[f]}\right.}$ Bernard Geffroy, ${ }^{[\mathrm{fl}]}$ \\ Arnaud Voituriez, ${ }^{*[b]}$ Angela Marinetti, ${ }^{*[b]}$ Muriel Hissler, ${ }^{*[a]}$ and Jeanne Crassous ${ }^{*[a]}$
}

\begin{abstract}
Herein, we report experimental physico-chemical and chiroptical properties of a series of phosphahelicenes, focusing on their UV/Vis absorption, luminescence, electronic circular dichroism (ECD), optical rotations, and circularly polarized luminescence. Furthermore, detailed analysis of absorption and ECD spectra performed with the help of quantum-chemical calculations allowed us to highlight general features of these helicenic phosphines. Finally, due to well-suited electrochemical properties and thermal stability, the systems were successfully used as emitters in organic light-emitting diodes.
\end{abstract}

\section{Introduction}

Helicenes are non-planar polycyclic aromatic hydrocarbons (PAHs) formed of ortho-condensed aromatic rings. Due to their peculiar helical and $\pi$-conjugated structure, they display unique chiroptical properties such as huge values of optical rotation (OR) parameters, intense electronic circular dichroism (ECD), and substantial circularly polarized luminescence (CPL) ${ }^{[1]}$ Accordingly, they have revealed appealing applications in many domains, particularly in optoelectronics. ${ }^{[2]}$ However, carbohelicenes generally display low fluorescence quantum yields $\left(\Phi_{\mathrm{FL}}\right)$ because their non-planar $\pi$-electron system triggers spin-orbit coupling (SOC) that accelerates intersystem crossing (ISC) pathways ( $\left.\Phi_{\text {ISC: }} \sim 0.9\right){ }^{[3]}$ An appealing strategy to modify emission properties of helicenes consists in introducing heteroatom(s) or heterocycle(s) in the helical structure. For example, significant improvements of helicenes' fluorescence properties have been recently achieved via introduction of such heterocycles as carbazole, ${ }^{[2 \mathrm{~b}, 4 \mathrm{a}]}$ maleimide, ${ }^{[2 \mathrm{e}, 4 \mathrm{~b}]}$ siloles, ${ }^{[4 \mathrm{c}]}$ oxaborine ${ }^{[4 \mathrm{~d}]}$ or azaborole. ${ }^{[4 \mathrm{e}]}$ Among other possible

[a] Institut des Sciences Chimiques de Rennes, UMR 6226 CNRS Université Rennes, Campus de Beaulieu, 35042 Rennes Cedex, France.E-mails: muriel.hissler@univ-rennes1.fr; jeanne.crassous@univ-rennes1.fr

[b] Institut de Chimie des Substances Naturelles CNRS UPR 2301 Université Paris-Sud, Université Paris-Saclay, 1, av. de la Terrasse, 91198 Gif-sur-Yvette, France. E-mails: arnaud.voituriez@cnrs.fr; angela.marinetti@cnrs.fr

[c] Laboratoire de Chimie, Université de Lyon, CNRS, Ecole Normale Supérieure de Lyon, UMR 5182, 46, Allée d'Italie, 69364 Lyon cedex 07, France.

[d] Faculty of Chemistry, Jagiellonian University, Gronostajowa 2, 30387 Krakow, Poland. E-mail: srebro@chemia.uj.edu.pl

[e] Department of Chemistry, San José State University, San José, CA 95192-0101, USA

[f] LICSEN, NIMBE, CEA, CNRS, Université Paris-Saclay, CEA Saclay, Gif-sur-Yvette CEDEX 91191, France.

Supplementary information for this article is given via a link at the end of the document. heterocycles, the phosphole ring is an interesting subunit for tuning emission properties of helicenes since phosphole derivatives are known to be efficient fluorescent emitters for organic light-emitting diodes (OLEDs). ${ }^{[5,6]}$ Recently, the introduction of a phosphole ring within a helicenic structure has enabled to construct a new class of helical systems, i.e. phosphahelicenes. ${ }^{[7,8]}$ Some of these helically chiral compounds, typified in Figure 1, appeared highly promising in enantioselective catalysis, ${ }^{[9]}$ both as chiral ligands for goldcatalyzed enantioselective enyne cycloisomerizations, ${ }^{[7 \mathrm{~d}-\mathrm{f}]}$ and as organocatalysts in asymmetric [3+2] cyclizations of $\gamma$-substituted allenes with electron-poor olefins. ${ }^{[\mathrm{gg}, \mathrm{h}]}$ However, the photophysical properties of these heterohelicenes, determining their potential application in OLEDs, have not been reported to date.

In this work, we describe the photophysical (i.e. UV/Vis absorption and fluorescence) and chiroptical properties (i.e. ECD and OR), and examine the CPL activity ${ }^{[4,10]}$ of a series of phosphahelicenes including phosphahelicene oxides $1-4,{ }^{[7 \mathrm{~b}, \mathrm{~d}]}$ and phosphahelicene sulfide $\mathbf{5}$ shown in Figure 1. The experimental data are supported and analyzed with the help of density functional calculations. The physical properties recorded in solution showed that the P-containing helicenes exhibit features expected for a material that can be inserted as active emitter in OLEDs. The results for a series of built OLED devices demonstrate the potential of these compounds for optoelectronic applications.

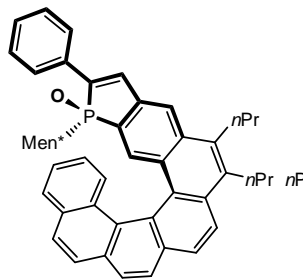

[6]-P-endo-1a

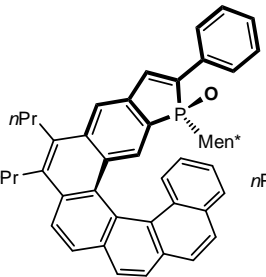

[6]-M-endo-1b

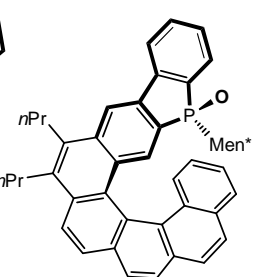

[6]-M-endo-2

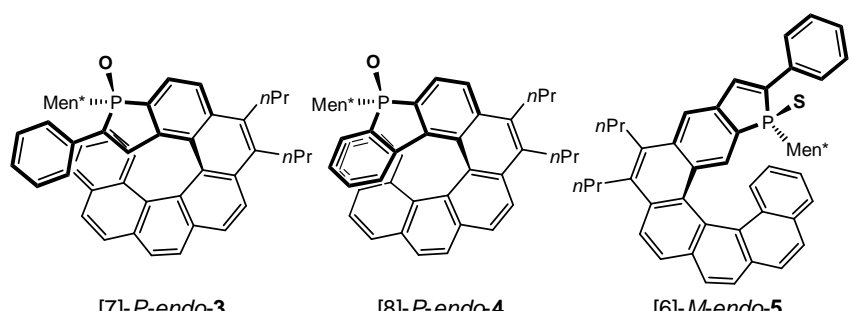

[7]-P-endo-3

[8]-P-endo-4

[6]-M-endo-5

Figure 1. Chemical structures of the phosphahelicenes 1-5 studied in this work. Men ${ }^{*}=$ I-menthyl. 


\section{Results and Discussion}

\section{UV/Vis absorption and emission of 1-5}

Compounds 1-4 have been prepared as described in our previous papers. ${ }^{[7 b, d]}$ The phosphahelicene sulfide $\mathbf{5}$ is a new compound. It has been synthesized from the corresponding oxide $\mathbf{1 b}$, as reported in the Supporting Information (SI).

Compounds $\mathbf{1 a}$ and $\mathbf{1 b}$ are benzooxophosphole derivatives that display carbo[6]helicene units meta-fused with one terminal oxophosphole ring containing a pendant phenyl ring at position $5{ }^{[7 \mathrm{~d}]}$ In both systems the menthyl group is directed toward the inner groove of the helix (endo isomer). These epimeric compounds can be considered as pseudo-enantiomers since they demonstrate reverse stereochemistry of the helix $(P / M)$ and of the $\mathrm{P}$ atom $\left(R_{\mathrm{P}} / S_{\mathrm{P}}\right)$ but unchanged stereochemistry of the chiral I-menthyl group. Consequently, as can be seen from Figure 2a, 1a,b display almost identical UV/Vis spectra consisting of sets of very strong absorption bands $\left(\varepsilon>20 \times 10^{3} \mathrm{M}^{-}\right.$ ${ }^{1} \mathrm{~cm}^{-1}$ ) between $250-350 \mathrm{~nm}$ (i.e. at 276, 323, $345 \mathrm{~nm}$, with the one around $276 \mathrm{~nm}$ reaching $\varepsilon \sim 50 \times 10^{3} \mathrm{M}^{-1} \mathrm{~cm}^{-1}$ ), and several bands of medium and low intensity $\left(2.7 \times 10^{3} \mathrm{M}^{-1} \mathrm{~cm}^{-1}<\varepsilon<\right.$ $20 \times 10^{3} \mathrm{M}^{-1} \mathrm{~cm}^{-1}$ ) between $350-450 \mathrm{~nm}$. It is also worth noting that the phosphahelicene sulfide $\mathbf{5}$, which has the same structure and stereochemistry as $\mathbf{1 b}$, displays only slightly
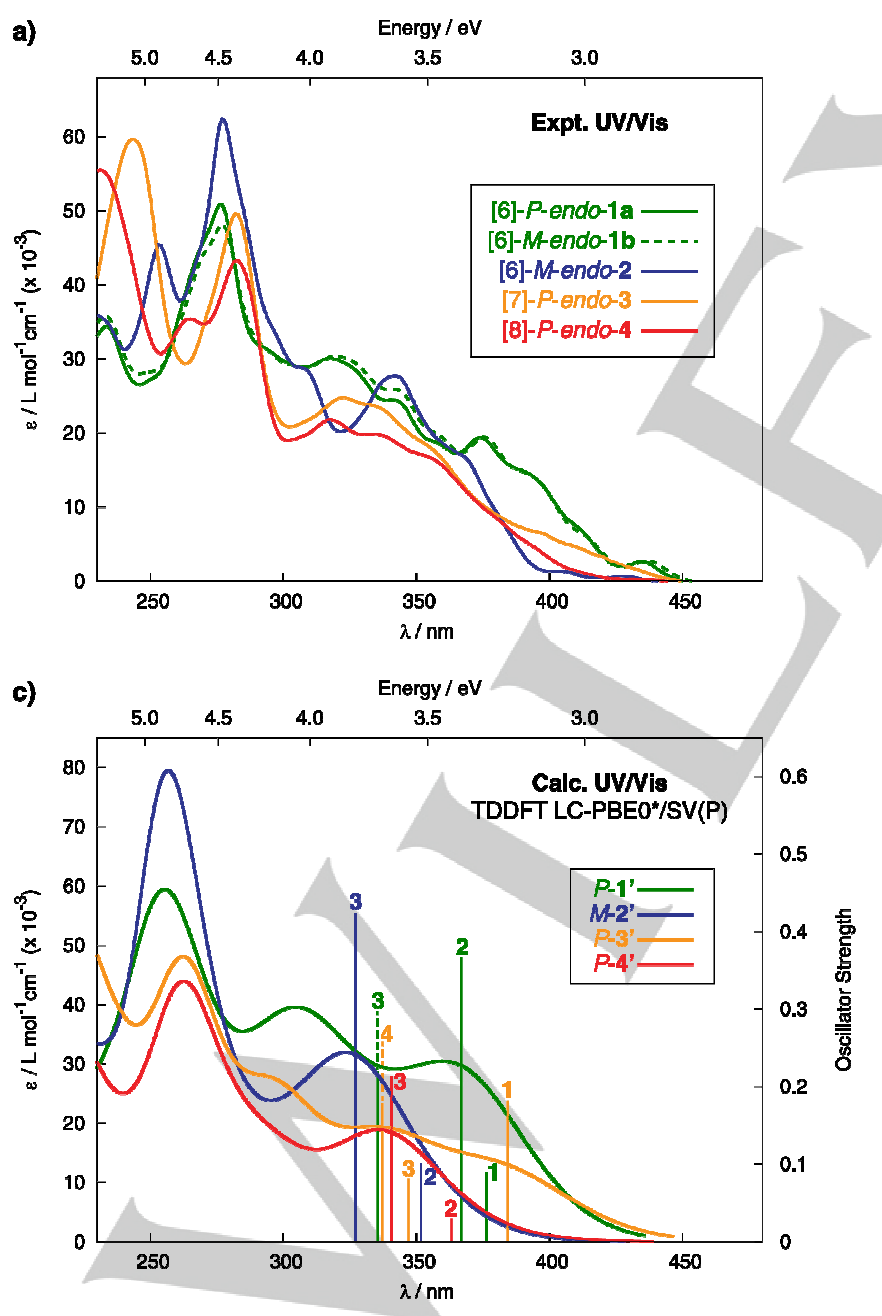

modified UV/Vis spectrum compared to compound 1a (see Figure $\mathrm{S} 25$ in the $\mathrm{SI}$ ). This shows that the nature of the Pfunction $(P=O$ in $\mathbf{1 b}$ vs. $P=S$ in 5, Figure $S 25)$ does not influence the corresponding absorption properties and implies that these properties are predominantly determined by the helical $\pi$-electron system of such compounds.

Compound 2 possesses a similar structure as carbo[6]helicenes $\mathbf{1 a}, \mathbf{b}$ but displays a fused benzophosphole terminal unit; ${ }^{[7 b]}$ accordingly it belongs to a family of phosphafluorenes oxides (dibenzophosphole oxides). Its UV/Vis spectrum shows very intense absorption bands $\left(\varepsilon>20 \times 10^{3} \mathrm{M}^{-1}\right.$ $\mathrm{cm}^{-1}$ ) between 250-350 nm (i.e. at 281, 309, $343 \mathrm{~nm}$, with the one at $281 \mathrm{~nm}$ reaching $\left.\varepsilon \sim 60 \times 10^{3} \mathrm{M}^{-1} \mathrm{~cm}^{-1}\right)$, one band of medium intensity at $370 \mathrm{~nm}\left(\varepsilon \sim 17 \times 10^{3} \mathrm{M}^{-1} \mathrm{~cm}^{-1}\right)$ followed by very weak bands at 414 and $438 \mathrm{~nm}\left(\varepsilon<10^{3} \mathrm{M}^{-1} \mathrm{~cm}^{-1}\right)$. Overall the low-energy tail in $\mathbf{2}$ is ipsochromically (blue) shifted as compared to $\mathbf{1 a}, \mathbf{b}$ and much less intense.

Compound $\mathbf{3}$ is a phospha[7]helicene oxide with an additional pendant phenyl ring at position 5 of the phosphole unit, ${ }^{[7 \mathrm{~d}]}$ while 4 corresponds to an oxidized phosphafluorene-type molecule with eight ortho-condensed rings; ${ }^{[76]}$ it can be therefore structurally classified as a phospha[8]helicene. It can be clearly seen from Figure 2 that the phosphahelicene oxides $\mathbf{3}$ and $\mathbf{4}$ display very similar UV/Vis spectra. Indeed, both $\mathbf{3}$ and $\mathbf{4}$ mainly

b)

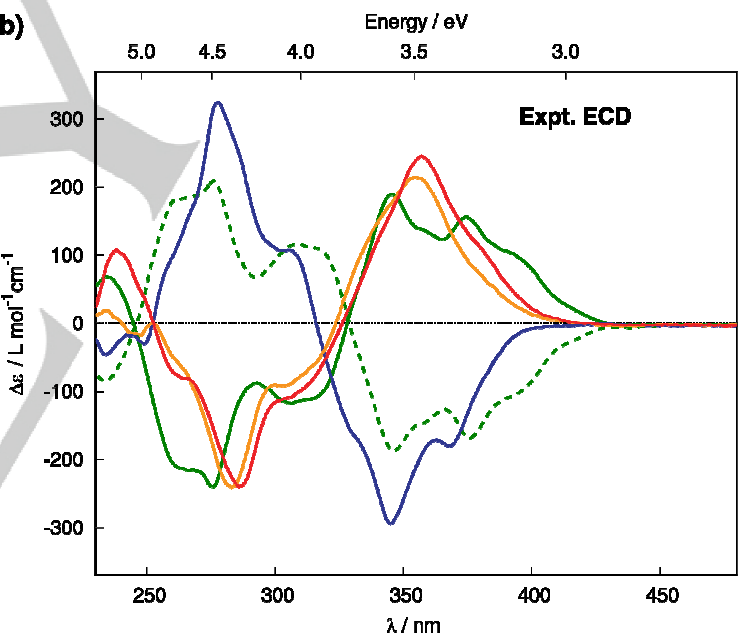

d)

d) Energy $/ \mathrm{eV}$

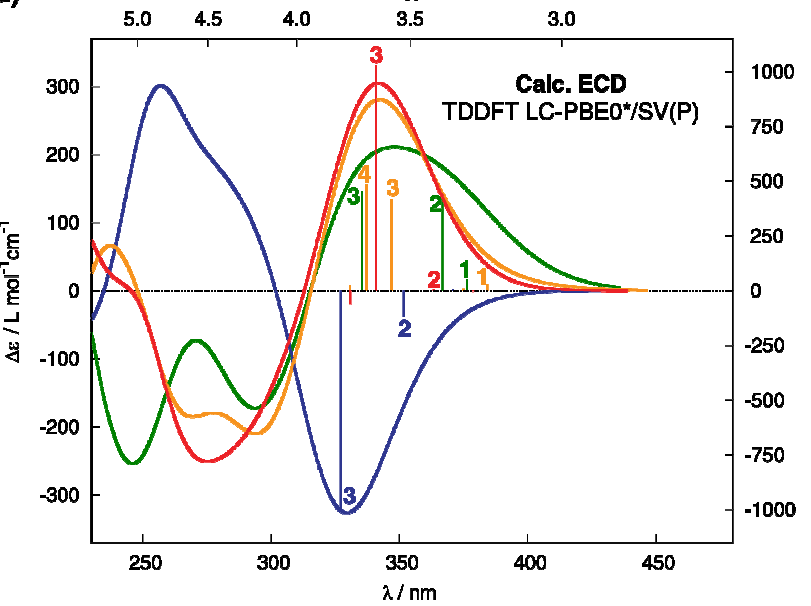

Figure 2. Comparison of the experimental UV/Vis (a) and ECD (b) spectra of phosphahelicenes 1-4 (in $\mathrm{CH}_{2} \mathrm{Cl}_{2}$, r.t., $c \sim 10^{-5} \mathrm{M}$ ) and simulated UV/Vis (c) and ECD (d) spectra of their corresponding truncated model systems $1^{\prime}-4^{\prime}$ (see Figure 3 ). No spectral shift has been applied. Calculated excitation energies and rotatory strengths indicated as 'stick' spectra. Numbered excitations correspond to those analyzed in detail. See also SI. 
show a strong band at $\sim 283 \mathrm{~nm}\left(\varepsilon \sim 45-52 \times 10^{3} \mathrm{M}^{-1} \mathrm{~cm}^{-1}\right)$ and a set of three other intense bands at $\sim 320,335$ and $355 \mathrm{~nm}$ $\left(\varepsilon \sim 17-25 \times 10^{3} \mathrm{M}^{-1} \mathrm{~cm}^{-1}\right)$, and one of moderate intensity at $395 \mathrm{~nm}\left(\varepsilon \sim 4-7 \times 10^{3} \mathrm{M}^{-1} \mathrm{~cm}^{-1}\right)$; compound 3 displays an additional low-energy tail above $400 \mathrm{~nm}\left(\varepsilon<5 \times 10^{3} \mathrm{M}^{-1} \mathrm{~cm}^{-1}\right)$. Overall, adding an ortho-fused phenyl ring, as in 4 , does not influence much the UV/Vis absorption when going from a phospha[7]- (3) to a phospha[8]helicene (4) and $\pi$-conjugation appears to be more extended when a phenyl group is grafted at position 5 of the phosphole ring (i.e. in $\mathbf{3}$ ).
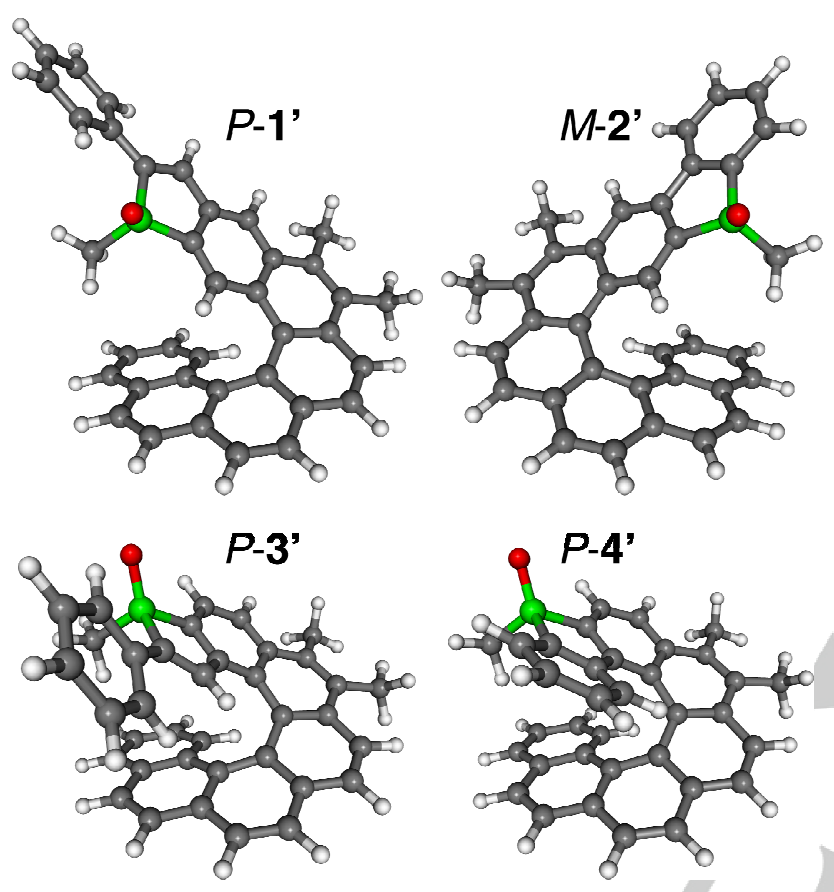

Figure 3. BP/SV(P)-optimized molecular structures of the systems 1'-4' studied as models for the phosphahelicene derivatives 1-4.

In order to provide insight into experimentally observed features of the oxo-phosphahelicene derivatives 1-4, (timedependent) DFT calculations ${ }^{[11]}$ were then performed on truncated systems with the I-menthyl and the $n$-propyl substituents replaced by methyls, referred to as $\mathbf{1}^{\prime}-\mathbf{4}^{\prime}$ in the following and presented in Figure 3 . The same set of calculations were also carried out for the full molecule 2 using available X-ray crystallographic data ${ }^{[7 b]}$ as a starting point in DFT geometry optimization. Results obtained for the two systems, i.e. 2' and 2, appear similar, which supports the adopted models. A full account of computational details and results of additional calculations are provided in the SI.

As can be seen in Figures $2 \mathrm{a}$ and 2c, the calculated (LC$\left.\mathrm{BPE} 0^{*} / \mathrm{SV}(\mathrm{P})\right)^{[12]} \mathrm{UV} / \mathrm{Vis}$ absorption spectra agree well with the experimental ones. In particular, the increase in intensity of the low-energy tail of $\mathbf{1}$ and $\mathbf{3}$ vs. 2 and $\mathbf{4}$ is correctly reproduced. Computational analysis shows that this increase is linked with a spatially more extended $\pi$-conjugation in the 'pendant-phenyl' compounds compared to their 'fused-phenyl' analogues, which is clearly visible in the corresponding frontier molecular orbitals (see Figure 4 and $\mathrm{SI}$ ). Note that the position of the phosphole ring relative to the helicene core (meta vs. ortho) seems not to affect a qualitative picture of frontier MOs in the examined systems, unlike the nature and substitution of their terminal ring (pendant vs. fused). Indeed, for the 5-phenyl-substituted phosphole derivatives 1' and 3', polarization of the electron density towards the phenyl moiety can be noticed in the isosurfaces of HOMO and LUMO, while for their benzo-fused analogues 2' and 4' those orbitals are almost evenly spread out over the whole molecule. Accordingly, the lowest-energy UV/Vis band in 1' and 3' can be assigned predominantly as $\pi-\pi^{*}$ transitions within helical $\pi$ electron system extended over terminal phosphole ring and the dangling phenyl substituent (Table 1 and Figure 4). The corresponding excitation of 3' (no. 1 calculated at $384 \mathrm{~nm}$ ) involves mainly the HOMO/LUMO pair. In the case of 1', two excitations with significant oscillator strengths were computed in this spectral region - no. $1(376 \mathrm{~nm})$ and no. $2(367 \mathrm{~nm})$ that correspond respectively to $\mathrm{HOMO} / \mathrm{LUMO}+1$, $\mathrm{HOMO}-$ 1,HOMO/LUMO and HOMO,HOMO-1/LUMO transitions. The contributions from the HOMO/LUMO+1 and HOMO-1/LUMO pairs in the lowest-energy excitations of 1' afford a partial phosphole-phenyl $\rightarrow$ helicene and helicene $\rightarrow$ phospholephenyl charge-transfer (CT) character. The lowest-energy excitation with sizeable oscillator strength in 2' and 4', no. 2 calculated at respectively 352 and $363 \mathrm{~nm}$, is noticeably blueshited and generally less intense as compared to those aforementioned for 1' and 3'. For both 2' and 4' the excitation has a large contribution from HOMO/LUMO pair that represents $\pi-\pi^{\star}$ transition within $\pi$-electron system delocalized across the whole molecule, and a smaller contribution from HOMO-1/LUMO+1 (for 2') / HOMO-1/LUMO (for 4') $\pi-\pi^{\star}$ transition mainly within helicene core. The observed blue-shift of the low-energy UV/Vis absorption correlates well with the increased HOMO-LUMO gap for 2', 4' vs. 1', 3' originating mostly from an increase (destabilization) of the LUMO energy level that is seen for the systems with fused terminal phenyl ring. Note that no noticeable involvement of $\mathrm{P}(\mathrm{O}) \mathrm{R}$ group was revealed in the low-energy excitations of 1'-4' implying that its main role is to rigidify the molecule, increase the size of the helical structure and extend its $\pi$-electron conjugation up to the terminal phosphole-phenyl rings. Its effect is thus very similar to that of $\mathrm{BR}_{2}$ moiety in our recently reported azaborahelicene derivatives. ${ }^{[4]}$

The emission properties of phosphahelicene oxides 1-4 and the phosphahelicene sulfide $\mathbf{5}$ were then examined in $\mathrm{CH}_{2} \mathrm{Cl}_{2}$ solutions at room temperature and in 2methyltetrahydrofuran (MeTHF) at $77 \mathrm{~K}$ at concentration of $10^{-}$ ${ }^{5} \mathrm{M}$. At room temperature, all compounds behave as blue fluorescent emitters, with emission wavelengths around 450 nm (Table 2). Beside compounds $\mathbf{3}$ and 4, systems 1, 2 and 5 show highly structured emission coming from the vibronic $\mathrm{C}=\mathrm{C}$ stretching modes, typical for helicoidal $\pi$-conjugated structures. The main effect of the helicenic core on the emission properties of $\mathbf{1 - 5}$ is however seen in the room temperature quantum yields $\left(\Phi_{\mathrm{f}}\right)$ and their low temperature emission spectra (see SI). Indeed, while helicenes with terminal phosphole oxide units, i.e. 1a,b and $\mathbf{3}$, display reasonable $\Phi_{f}(7-11 \%)$, a drastical decrease in its value is observed for the benzo-fused phospha[8]helicene oxide $4\left(\Phi_{f}\right.$ $=2 \%)$ and the phosphahelicene sulfide $5\left(\Phi_{f}=1 \%\right)$. The highest quantum yield is obtained for the phosphafluorenetype phospha[6]helicene oxide $2\left(\Phi_{f}=32 \%\right)$. Furthermore, at $77 \mathrm{~K}$, the emission spectra of the rigid phosphafluorene-based 
compounds 2 and $\mathbf{4}$ demonstrate fluorescence emission accompanied by phosphorescence which is typical for helicenic structures. ${ }^{[4 \mathrm{e}]}$ For compounds $\mathbf{1}, 3$ and $\mathbf{5}$, which display pendant phenyl rings at position 5 of the phosphole ring, only fluorescent emission is observed indicating that such freely rotating group promotes non-radiative deactivation processes. This observation shows the importance of a choice of a phosphole substructure, phosphafluorene vs. benzophosphole, since different deactivation pathways of the excited state are noticed.

Table 1. Selected dominant excitations and occupied (occ) - unoccupied (unocc) MO pair contributions (greater than 10\%) of the model phosphahelicene derivatives 1'-4'.

\begin{tabular}{|c|c|c|c|c|c|c|c|}
\hline Excitation & $E / \mathrm{eV}$ & $\lambda / \mathrm{nm}$ & $f$ & $R / 10^{-40} \mathrm{cgs}$ & occ no. & unocc no. & $\%$ \\
\hline \multicolumn{8}{|l|}{$P-1$} \\
\hline \multirow[t]{3}{*}{1} & 3.29 & 376 & 0.089 & 51.06 & 136 & 138 & 30.8 \\
\hline & & & & & 135 & 137 & 28.2 \\
\hline & & & & & & 137 & 19.9 \\
\hline \multirow[t]{2}{*}{2} & 3.38 & 367 & 0.366 & 424.46 & 136 & 137 & 65.1 \\
\hline & & & & & 135 & 137 & 16.8 \\
\hline \multirow[t]{3}{*}{3} & 3.70 & 335 & 0.219 & 452.64 & 135 & 138 & 43.8 \\
\hline & & & & & 136 & 138 & 20.0 \\
\hline & & & & & 134 & 137 & 11.7 \\
\hline \multicolumn{8}{|l|}{$M-2^{\prime}$} \\
\hline \multirow[t]{2}{*}{2} & 3.53 & 352 & 0.102 & -116.97 & 129 & 130 & 76.5 \\
\hline & & & & & 128 & 131 & 12.2 \\
\hline \multirow[t]{3}{*}{3} & 3.79 & 327 & 0.424 & -992.61 & 129 & 131 & 36.8 \\
\hline & & & & & 128 & 131 & 25.3 \\
\hline & & & & & 128 & 130 & 21.6 \\
\hline \multicolumn{8}{|l|}{$P-3^{\prime}$} \\
\hline 1 & 3.23 & 384 & 0.182 & 27.78 & 136 & 137 & 83.4 \\
\hline \multirow[t]{2}{*}{3} & 3.57 & 347 & 081 & 415.27 & 136 & 139 & 55.2 \\
\hline & & & & & 134 & 137 & 18.1 \\
\hline \multirow[t]{4}{*}{4} & 3.68 & 337 & 0.179 & 483.04 & 135 & 137 & 40.8 \\
\hline & & & & & 136 & 138 & 14.4 \\
\hline & & & & & 135 & 139 & 12.5 \\
\hline & & & & & 135 & 138 & 10.7 \\
\hline \multicolumn{8}{|l|}{$P-4$} \\
\hline \multirow[t]{2}{*}{2} & 3.41 & 363 & 0.029 & 4.54 & 129 & 130 & 68.3 \\
\hline & & & & & 128 & 130 & 12.3 \\
\hline \multirow[t]{3}{*}{3} & 3.64 & 341 & 0.213 & 1026.96 & 129 & 131 & 37.3 \\
\hline & & & & & 128 & 130 & 22.8 \\
\hline & & & & & 127 & 130 & 21.6 \\
\hline
\end{tabular}


HOMO-1
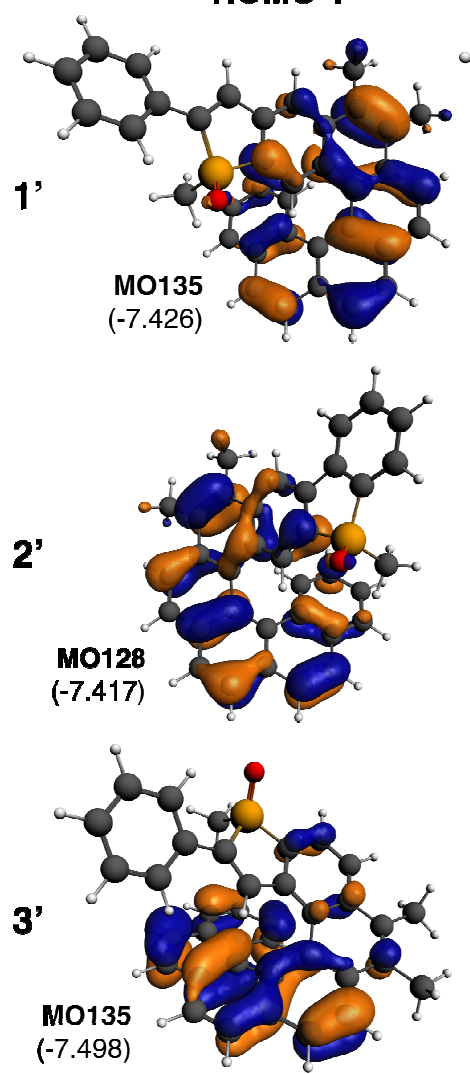

$(-7.498)$

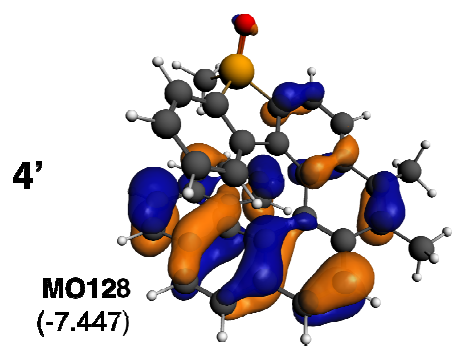

HОMO
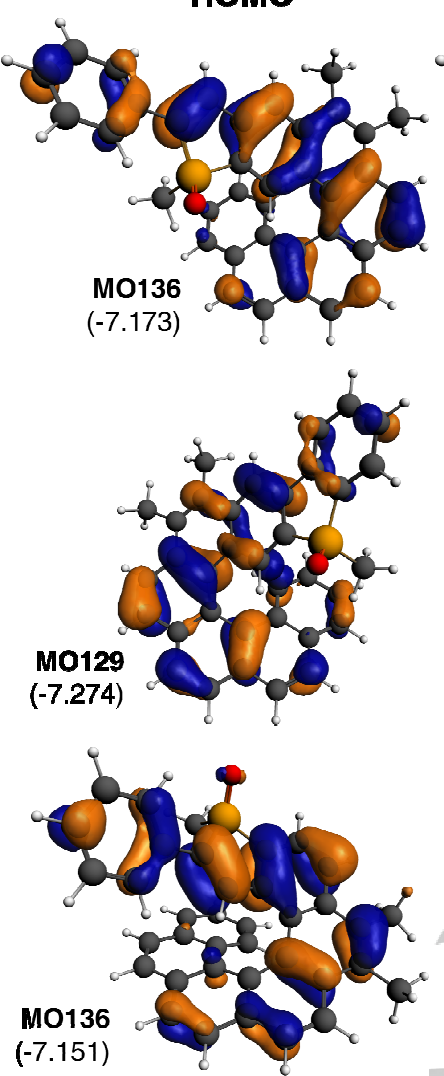

$(-0.807)$

LUMO
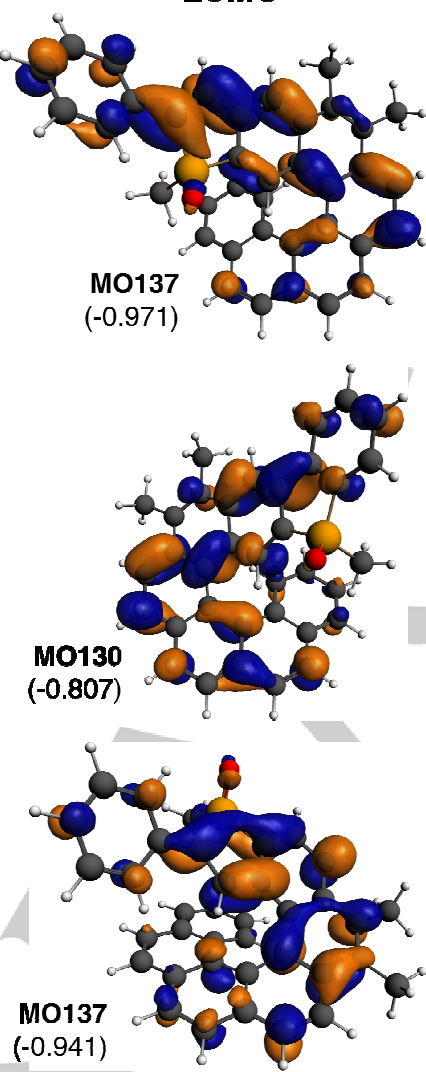

\section{LUMO+1}

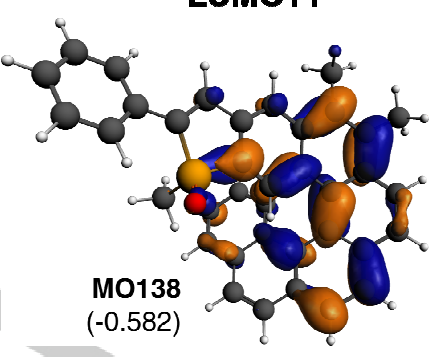

$(-0.582)$
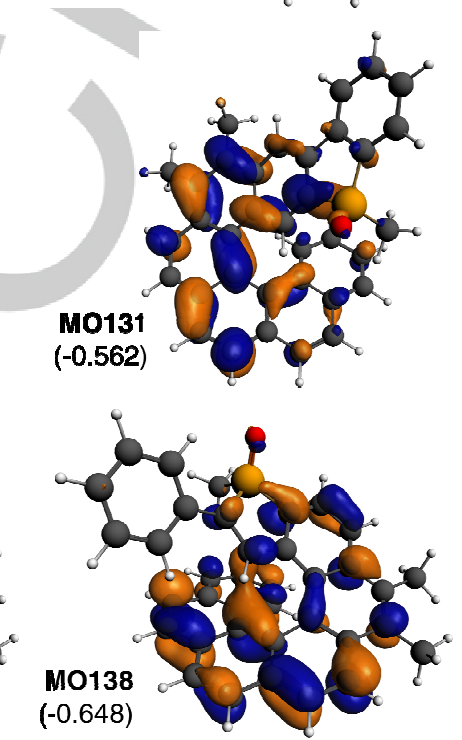
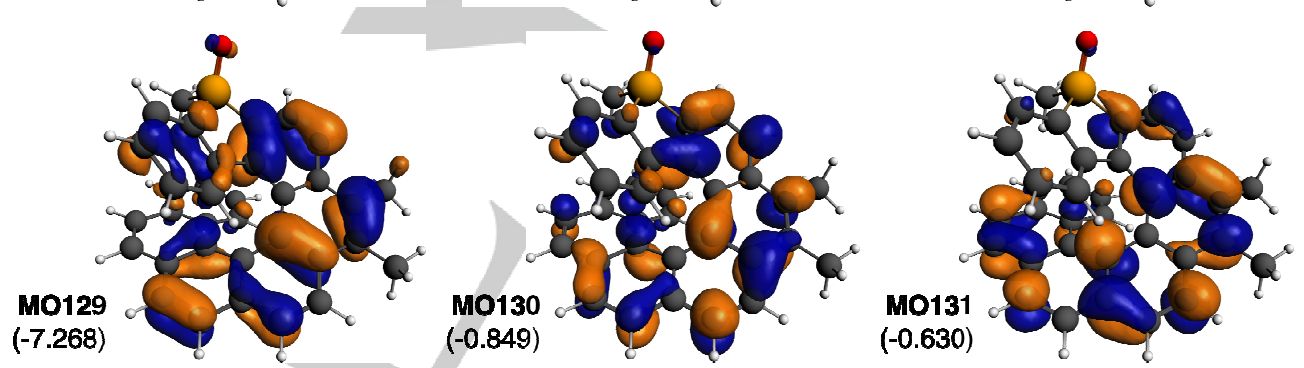

Figure 4. Isosurfaces ( $0.03 \mathrm{au}$ ) of frontier MOs of $1^{\prime}-4^{\prime}$. Values listed in the parentheses are the corresponding orbital energies, in eV.

\section{Electrochemical properties of 1-5}

The electrochemical behavior of 1-5 was investigated by cyclic voltammetry (CV). The CV curves were recorded in degassed $\mathrm{CH}_{2} \mathrm{Cl}_{2}$ solutions that contained $0.2 \mathrm{M}$ of $n$ tetrabutylammonium hexafluorophosphate $\left(\mathrm{Bu}_{4} \mathrm{NPF}_{6}\right)$ as the supporting electrolyte and $10^{-3} \mathrm{M}$ of phosphahelicene. The corresponding redox properties are summarized in Table 2. The compounds 1, 3 and $\mathbf{5}$ demonstrate similar behavior. They are oxidized and reduced at around $+0.95 \mathrm{~V}$ and $-2.30 \mathrm{~V}\left(\mathrm{vs}\right.$. $\left.\mathrm{Fc} / \mathrm{Fc}^{+}\right)$, respectively, however only 3 presents reversible redox processes. The nature of the P-function seems to play rather a minor role. The phosphahelicene sulfide $\mathbf{5}$ is slightly easier to oxidize and slightly more difficult to reduce which implies an energetic destabilization of the HOMO and the LUMO levels. The electrochemical HOMO-LUMO gap remains however similar for all three compounds bearing the pendant phenyl substituent. The phosphafluorene-type compounds 2 and $\mathbf{4}$ exhibit only an irreversible oxidation process at around $+0.95 \mathrm{~V}\left(\mathrm{vs}\right.$. $\left.\mathrm{Fc} / \mathrm{Fc}^{+}\right)$; no reduction is seen in the electrochemical windows. These data show that a different redox behavior can be observed depending directly on the organophosphorus substructure. 
Table 2. UV/Vis absorption and emission data for phosphahelicenes 1-5 along with their electrochemical properties and decomposition temperature values. See also SI.

\begin{tabular}{|c|c|c|c|c|c|c|c|}
\hline Compound & $\begin{array}{c}\text { Absorption } \\
\lambda_{\max } / \mathrm{nm}\left(\varepsilon / \mathrm{M}^{-1} \mathrm{~cm}^{-1}\right)^{[\mathrm{a}]}\end{array}$ & $\begin{array}{l}\text { Emission } \\
\text { r.t. }^{\text {[a] }} \\
\lambda_{\max } / \mathrm{nm}\end{array}$ & $\begin{array}{l}\Phi_{\mathrm{f}} \\
\text { r.t. }{ }^{[\mathrm{b}]}\end{array}$ & $\begin{array}{l}\text { Emission } \\
77 \mathrm{~K}^{[\mathrm{c}]} \\
\lambda_{\max } / \mathrm{nm}\end{array}$ & $\mathrm{E}^{\mathrm{ox}} / \mathrm{V}^{[\mathrm{d}]}$ & $E^{\text {red }} / V^{[d]}$ & $\mathrm{T}_{\text {decomp. }} /{ }^{\circ} \mathrm{C}{ }^{[\mathrm{f}]}$ \\
\hline $1 a$ & $\begin{array}{c}278(55700), 317(37200), \\
347(29100), 375(22800), \\
384(17300), 415(7500) \\
436(3700)\end{array}$ & $\begin{array}{l}449,476 \\
509\end{array}$ & 0.10 & $\begin{array}{c}F: 432,443, \\
465,501,533\end{array}$ & +0.96 & & 332 \\
\hline $1 b$ & $\begin{array}{l}278(55100), 320(37000), \\
334(30500), 360(23300), \\
376(24000), 395(17200), \\
414(7800), 438(4100)\end{array}$ & $\begin{array}{l}455,481 \\
514\end{array}$ & 0.07 & $\begin{array}{l}F: 439,446 \\
471,504,541\end{array}$ & $+0.95^{[\mathrm{e}]}$ & $-2.28^{[e]}$ & 334 \\
\hline 2 & $\begin{array}{c}281(60100), 309(29400), \\
343(29100), 370(16700), \\
382(8500), 407(1180) \\
430(770)\end{array}$ & $\begin{array}{l}439,465 \\
493\end{array}$ & 0.32 & $\begin{array}{c}F: \\
430,458,488 \\
P: 548,594, \\
645\end{array}$ & $+0.96^{[\mathrm{e}]}$ & - & 352 \\
\hline 3 & $\begin{array}{c}284(52600), 322(26900) \\
338(25000), 356(18700) \\
435(1900)\end{array}$ & $\begin{array}{c}456,472 \\
\text { (broad) }\end{array}$ & 0.11 & $\begin{array}{c}F: 441,471 \\
498\end{array}$ & +0.94 & -2.20 & 335 \\
\hline 4 & $\begin{array}{c}282(45000), 317(21700) \\
334(19800), 357(17500) \\
383(8400), 408(1100) \\
435(800)\end{array}$ & 448,465 & 0.02 & $\begin{array}{c}F: \\
437,465,495 \\
P: 583,635\end{array}$ & $+0.94^{[\mathrm{e}]}$ & - & 344 \\
\hline 5 & $\begin{array}{c}278(53500), 320(42800) \\
345(35400), 380(26600) \\
440(4100)\end{array}$ & $\begin{array}{l}456,479 \\
516\end{array}$ & 0.01 & $\mathrm{~F}: 443,472$ & $+0.93^{[\mathrm{e}]}$ & $-2.33^{[\mathrm{e}]}$ & \\
\hline
\end{tabular}

${ }^{[a]}$ Measured in $\mathrm{CH}_{2} \mathrm{Cl}_{2}$ at $c=10^{-5} \mathrm{M}$ at room temperature. ${ }^{[\mathrm{b}]}$ Measured relative to quinine sulfate $\left(\mathrm{H}_{2} \mathrm{SO}_{4}, 0.1 \mathrm{M}\right), \Phi_{\mathrm{f} \text { ref }}=0.546 \pm 15 \%$. ${ }^{[\mathrm{c}]} \mathrm{Measured}$ in MeTHF at $C$ $=10^{-5} \mathrm{M}$ at $77 \mathrm{~K}$. ' $\mathrm{F}$ ' - fluorescence. ' $\mathrm{P}$ ' - phosphorescence. ${ }^{[\mathrm{d}]}$ Obtained during cyclic voltammetric investigations in $0.1 \mathrm{M} \mathrm{Bu}_{4} \mathrm{NPF}_{6}$ in $\mathrm{CH}_{2} \mathrm{Cl}_{2}$. $\mathrm{Platinum} \mathrm{electrode}$ diameter: $1 \mathrm{~mm}$, sweep rate: $200 \mathrm{mV} \mathrm{s}^{-1}$. All values referenced to the reversible formal potential of the ferrocene/ferrocenium couple. ${ }^{[\mathrm{e}]}$ Irreversible process. ${ }^{[\mathrm{f}]}$ Measured by thermogravimetric analysis at $10 \%$ decomposition.

\section{Chiroptical properties of 1-5}

The electronic circular dichroism spectra (ECD, Figure $2 b$ and SI) and optical rotation parameters (ORs, Table 3) of compounds 1-5 revealed features considered as classical for helicene derivatives. The two epimeric $M$ and $P$ phosphahelicene oxides 1a,b display mirror-image ECD spectra with [6]- $P$-endo-1a, used as an example, showing several strong negative bands at $260,274,304$, and $315 \mathrm{~nm}\left(\Delta \mathcal{E}=-200,-235,-116\right.$, and $-110 \mathrm{M}^{-1}$ $\mathrm{cm}^{-1}$, respectively), several intense positive bands at 346,355 , 372 , and $392 \mathrm{~nm}\left(\Delta \varepsilon=+180,+140,+150\right.$, and $+103 \mathrm{M}^{-1} \mathrm{~cm}^{-1}$, respectively), and a very weak one at $418 \mathrm{~nm}\left(\Delta \varepsilon=+17 \mathrm{M}^{-1} \mathrm{~cm}^{-}\right.$ $\left.{ }^{1}\right)$. The benzo-fused helicene [6]-M-endo-2 demonstrates a generally similar ECD spectrum to its phenyl-substituted helicene analogue [6]- $M$-endo-1b but overall more intense and with less low-energy bands: $\Delta \varepsilon=+82,+317,-155,-285$, and $-177 \mathrm{M}^{-1} \mathrm{~cm}^{-}$ 1 at 258, 276, 329, 343, and $366 \mathrm{~nm}$, respectively. Helicenes [7]$P$-endo-3 and [8]-P-endo-4 display almost identical ECD spectra, with negative intensity centered at around 260,280 , and $305(\Delta \varepsilon$ $\sim-50,-240$, and $-95 \mathrm{M}^{-1} \mathrm{~cm}^{-1}$, respectively) and a positive band around $355 \mathrm{~nm}\left(\Delta \varepsilon \sim+215\right.$ to $\left.+240 \mathrm{M}^{-1} \mathrm{~cm}^{-1}\right)$ with unresolved vibronic structure and higher intensity than the corresponding band in [6]-P-endo-1a. Finally, note that the phosphahelicene sulfide [6]-M-endo-5 displays ECD spectrum very similar to that of its oxide analogue [6]-M-endo-1b, especially in the low- and medium-energy (> $330 \mathrm{~nm}$ ) spectral regions (see Figure S26), confirming minor influence of the P-function on the (chir)optical absorption properties of such compounds (see above).

The experimental ECD envelopes for 1-4 are well reproduced by the TDDFT calculations performed for the corresponding truncated model systems 1'-4' (see Figure 2b,d). Analysis of MOpair contributions to dominant excitations in the low- and medium-energy regions of the simulated ECD spectra (Table 1, Figure 4 , and $\mathrm{SI}$ ) demonstrates predominant $\pi-\pi^{*}$ character of the main positive / negative band in $P-1, P-3, P-4 / M-2$ with, indeed, negligible involvement of $\mathrm{P}(\mathrm{O}) \mathrm{R}$ group MOs likely due to their lower orbital energies. For the isoelectronic benzo-fused phospholes 2' and 4' the band originates mainly from excitation no. 3 calculated at 327 and $341 \mathrm{~nm}$, respectively. The excitation involves HOMO,HOMO-1/LUMO+1, HOMO-1/LUMO pairs for 2' and HOMO/LUMO+1, HOMO-1,HOMO-2/LUMO for 4' that all correspond to $\pi-\pi^{*}$ transitions within helicene $\pi$-electron core with benzophosphole $\rightarrow$ helicene and helicene $\rightarrow$ benzophosphole CT signature due to the fact that the engaged MOs are centered in 
different parts of the compound's $\pi$-system. For the phenylsubstituted phosphahelicenes 1' and 3' two excitations with sizeable rotatory strength values were found to be responsible for the experimentally observed main positive ECD intensity: nos. 2 and 3 for 1' and nos. 3 and 4 for 3'. The higher-energy (shorter-wavelength) excitations, no. 3 for 1' and no. 4 dor 3', calculated for both systems at around $336 \mathrm{~nm}$, have assignment similar to that described above for 2' and 4' (see Table 1, Figure 4 , and $\mathrm{SI}$ ). The lower-energy excitations, no. 2 for 1' and no. 3 for 3', with contributions from HOMO,HOMO-1/LUMO and $\mathrm{HOMO} / \mathrm{LUMO}+2$, HOMO-2/LUMO pairs, respectively, correspond to $\pi$ - $\pi^{\star}$ transitions involving $\pi$-system delocalized generally across the whole molecule with non-negligible CT component. Due to its predominant HOMO/LUMO character the

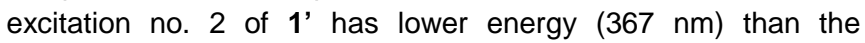
excitation no. 3 of 3' (347 nm) and in consequence it appears responsible for additional low-energy ECD band observed in the experimental spectrum of 1 . The above assignment of the simulated ECD spectra of 1'-4' confirms that the primary effect of 1-oxophosphole unit in $\mathbf{1 - 5}$ is to extend helicoidal $\pi$-electron system up to the phenyl substituent of the phosphole ring that can be involved then in electronic $\pi$ - $\pi^{\star}$-type transitions. ${ }^{[4 \mathrm{e}]}$

The experimental specific (resp. molar) optical rotations of phosphahelicenes 1-5 are gathered in Table 3. Their magnitudes all fall within the same range, i.e. from $+2145^{\circ} \mathrm{cm}^{3} \mathrm{dm}^{-1} \mathrm{~g}^{-1}$ (resp. $+15000^{\circ} \mathrm{cm}^{2} \mathrm{dmol}^{-1}$ ) for [7]- $P$-endo-3 to +2670 (resp. +17950 ) for [8]- $P$-endo-4. Although it is interesting to note that while $\mathbf{3}$ and $\mathbf{4}$ display almost identical ECD spectra they show the lowest and highest optical rotation values of the whole series, no visible relation between structures of the examined phosphahelicenes and their ORs is observed. This can be however due to experimental errors in the measurements that are estimated to be around $\pm 5-10 \%$. Calculations performed for the truncated model systems 1'-4' predict qualitatively consistent OR parameters for all the molecules but they give noticeably larger values than the corresponding experimental ones for 1-4 (Table 3 and $\mathrm{SI}$ ). The overestimation is slightly higher for values obtained using the LC-PBE0* functional employing an "optimally tuned' range-separation parameter for a helicene ${ }^{[12]}$ than for those calculated with BHLYP and it seems to be predominantly linked with the replacement of the chiral menthyl group in 1-4 by the achiral methyl in 1'-4'. Indeed, computations for the full system 2 leads to visibly lower OR values. This indicates that although the menthyl substituent seems not to determine to any significant degree ECD spectra of phosphahelicenes 1-5 (see SI), it clearly affects their optical rotations. Note that $n$-propyl groups present in 1-5 can also indirectly - by affecting molecular structures of these systems - influence the corresponding OR values. ${ }^{[13]}$

Circularly polarized luminescence (CPL) activity, which combines emission and chirality, is a particularly appealing chiroptical property of organic chiral chromophores such as helicenic derivatives. ${ }^{[10]}$ There is indeed a growing interest in $\mathrm{CPL},{ }^{[14]}$ and $\mathrm{CPL}$-emitters have recently been incorporated into OLEDs to obtain circularly polarized (CP) OLEDs. ${ }^{[2 h]}$ The CPL activity of phosphahelicenes 1-5 was therefore also examined via measurements in degassed $\mathrm{CH}_{2} \mathrm{Cl}_{2}$ solutions at concentrations around $1 \times 10^{-3} \mathrm{M}$. The epimeric helicenes [6]- $P$-endo-1a and [6]$M$-endo-1b display mirror-image CPL spectra (Figure 5) with luminescence anisotropy factor glum $=+8 \times 10^{-4}$ and $-7 \times 10^{-4}$ at 452 $\mathrm{nm}$ (excitation at $404-416 \mathrm{~nm}$ ) for $P-1 \mathbf{a}$ and $M-1 \mathbf{b}$, respectively.
These values are in the same range as for organic helicene derivatives, ${ }^{[1]}$ and very similar to $g_{\text {lum }}$ determined for triphenylenebased phospha[7]helicene and benzopicene-based phospha[9] helicene whose CPL activity has been very recently reported. ${ }^{[8 d]}$ As for other phosphahelicenes 2-5, no measurable $\mathrm{CPL}$ was detected. These compounds may either undergo decompositon when subjected to the Xenon lamp of the CPL experimental set-up or display too low $\mathrm{CPL}$ signal to be measured.

Table 3. Experimental and calculated optical rotation parameters of the phosphahelicene derivatives 1-5 studied in this work. Specific OR $[\alpha]_{D}$ in deg $\mathrm{cm}^{3} \mathrm{dm}^{-1} \mathrm{~g}^{-1}$ and molar OR $[\phi]_{D}$ in deg $\mathrm{cm}^{2} \mathrm{dmol}^{-1}$.

\begin{tabular}{|c|c|c|c|c|}
\hline \multirow{3}{*}{ System } & \multirow{2}{*}{\multicolumn{2}{|c|}{ Expt. $^{[\mathrm{a}]}$}} & \multicolumn{2}{|c|}{ Calc. $^{[b]}$} \\
\hline & & & \multirow{2}{*}{$\frac{\text { BHLYP }}{[\phi]_{D}}$} & \multirow{2}{*}{$\frac{\text { LC-PBE0 }}{[\phi]_{D}}$} \\
\hline & {$[\alpha]_{D}^{23}$} & {$[\phi]_{D}^{23}$} & & \\
\hline$P-1 a$ & 2340 & 16350 & \multirow{2}{*}{23551} & \multirow{2}{*}{25380} \\
\hline$M-1 \mathbf{b}$ & -2486 & -17380 & & \\
\hline$M-2$ & -2450 & -16520 & $\begin{array}{c}-18319 \\
(-13605)\end{array}$ & $\begin{array}{l}-19977 \\
(-14595)\end{array}$ \\
\hline$P-3$ & 2145 & 15000 & 18199 & 20349 \\
\hline$P-4$ & 2670 & 17950 & 19198 & 21107 \\
\hline$M-5$ & -2280 & -16280 & - & - \\
\hline
\end{tabular}

[a] Measured in $\mathrm{CH}_{2} \mathrm{Cl}_{2}$ at $C \sim 10^{-5} \mathrm{M}$. ${ }^{[\mathrm{b}]}$ Values for $P-\mathbf{1}^{\prime}, M-\mathbf{2}^{\prime}$ and $M-2$ (in parentheses), $P$-3', and $P$-4'. See also SI.

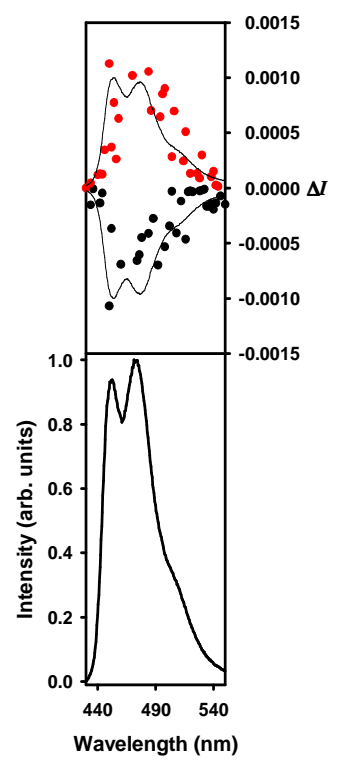

Figure 5. CPL (top, solid lines added to show luminescence spectral line shape) and total luminescence (bottom) spectra of $P$-1a (top red) and $M-1 \mathbf{b}$ (top black) in degassed dichloromethane solution $\left(c=10^{-3} \mathrm{M}\right)$ at $295 \mathrm{~K}$, upon excitation at 404 and $416 \mathrm{~nm}$, respectively.

\section{OLED application}

All the compounds 1-5 present decomposition temperature above $330^{\circ} \mathrm{C}$ (Table 2) indicating good thermal stability which is 
a critical issue for OLED device stability and lifetime. However, taking into account their (photo)physical properties, only 2 could be of potential use as emitting material (EM) in OLEDs. To investigate its performance in OLEDs, we built a series of OLED devices with structures of indium tin oxide (ITO) / copper phthalocyanine (CuPc) (10 nm) / N,N'-di(1-naphtyl)-N,N'diphenyl-(1,1'-biphenyl)-4,4'diamine ( $\alpha$-NPB) (40 nm) / tris $(4-$ carbazoyl-9-ylphenyl)amine (TCTA) (10 nm) / 1,3-bis $(\mathrm{N}-$ carbazolyl)benzene (m-CP) : 2 (4 or $3 \%)(20 \mathrm{~nm}) / 2,2^{\prime}, 2 "-(1,3,5-$ benzinetriyl)-tris(1-phenyl-1-H-benzimidazole) (TPBi) $(50 \mathrm{~nm}) /$ $\mathrm{LiF}(1.2 \mathrm{~nm})$ / $\mathrm{Al}(100 \mathrm{~nm})$ where CuPc is the hole injection layer, $\alpha$-NPB and TCTA are the hole transporting layers, and TPBi is the electron transporting layer (see SI for details).

Since phosphahelicene 2 presents irreversible redox processes, it was used as a dopant in an $\mathrm{m}$-CP matrix (doping rate of $3 \%$ and $4 \% \mathrm{w}$ for device $\mathbf{A}$ and $\mathrm{B}$, respectively; Table 4$)$. As evidenced by the CIE coordinates, a blue fluorescent electroluminescence was obtained, spectrum of which is not affected by the increase of the current density and matches the emission of $\mathbf{2}$ in the solid state (Figure S36). The emission of m$\mathrm{CP}$ is only slightly observed at $408 \mathrm{~nm}$, which indicates an almost quantitative energy transfer from the m-CP layer to the emitter 2. For devices $\mathbf{A}$ and $\mathbf{B}$, luminance and external quantum efficiency are moderate likely due to a low charge transport. The current efficiency (CE) reaches a constant plateau for current densities above $10 \mathrm{~mA} / \mathrm{cm}^{2}$ (Figures S37-38). The maximum CE value is 0.94 and $0.75 \mathrm{~cd} / \mathrm{A}$ for device $\mathbf{A}$ and $\mathbf{B}$, respectively. By increasing the dopant concentration in the $\mathrm{m}-\mathrm{CP}$ matrix from $3 \%$ in device $\mathbf{A}$ to $4 \%$ in B the efficiency of the OLED drops dramatically from $94 \%$ to $52 \%$. Finally, with the aim of preparing CP-OLEDs, i.e. OLEDs emitting a circularly polarized light, the polarization of the light was measured by using a quater-wave polarizer. However, no circular polarization could be detected with this type of device. This result is probably due to the very low glum of compound 2, which could not even be measured in our CPL apparatus. Further studies are currently performed towards optimizing the OLEDs structure in order to produce CP light.

Table 4. Electroluminescent performance of OLED devices incorporating compound $\mathbf{2}$ in emitting layer.

\begin{tabular}{ccccccc}
\hline Device & $\begin{array}{c}\text { Doping } \\
\text { rate of } 2 \\
(\%)\end{array}$ & $\begin{array}{c}\mathrm{V}_{\text {on }}{ }^{[\mathrm{a}]} \\
(\mathrm{V})\end{array}$ & $\begin{array}{c}\mathrm{EQE}^{[\mathrm{b}]} \\
(\%)\end{array}$ & $\begin{array}{c}\mathrm{CE}^{[\mathrm{b}]} \\
(\mathrm{cd} / \mathrm{A})\end{array}$ & $\begin{array}{c}\mathrm{PE}^{[\mathrm{b}]} \\
(\mathrm{Im} / \mathrm{W})\end{array}$ & $\begin{array}{c}\text { CIE color } \\
\text { coordinates }\end{array}$ \\
\hline A & 3 & 4.1 & 0.94 & 0.94 & 0.36 & $0.21 ; 0.22$ \\
\hline B & 4 & 4.1 & 0.52 & 0.75 & 0.24 & 0,$20 ; 0,28$ \\
\hline
\end{tabular}

[a] Threshold voltage recorded at luminance of $1 \mathrm{~cd} / \mathrm{m}^{2}$, ${ }^{[b]} \mathrm{EQE}=$ external quantum efficiency, $\mathrm{CE}=$ current efficiency, and $\mathrm{PE}=$ power efficiency recorded at $30 \mathrm{~mA} / \mathrm{cm}^{2}$ corresponding to the maximum efficiency of the devices.

\section{Conclusions}

In conclusion, careful analysis of experimental and theoretical photophysical and chiroptical features of phosphahelicenes 1-5 enabled us to reveal factors that influence properties of such compounds. We have highlighted, for instance, the role of the pendant phenyl substituent of the terminal phosphole unit, compared to the fused benzo-group, in the overall extended $\pi$-conjugation of phosphahelicene derivatives.
The pendant phenyl group also strongly influences the emissive properties of such systems, both at room temperature and at $77 \mathrm{~K}$ with the occurence of deactivating processes that are not observed for the more rigid benzo-fused derivatives. It was also showed that stereochemistry of the menthyl subsituent present at the P-atom has no strong influence on the ECD spectra of phosphahelicenes 1-5, but may affect their corresponding optical rotation values. On the other hand, the nature of the P-function $(P=O$ vs. $P=S$ ) was found to have overall negligible influence on all photophysical and chiroptical properties of such compounds. Finally, we showed that the phosphahelicene derivative [6]- $M$ endo-2 which demonstrated the best performance in terms of emission, electrochemical properties and thermal stability among considered here systems, could be used as a blue-emitting chiral dopant in an OLED device. Further studies are ongoing toward the manufacture of phosphahelicene-based OLEDs displaying circularly polarized electroluminescence.

\section{Experimental Section}

Experimental and computational details are described in the Supplementary Information.

\section{Acknowledgements}

We thank the Ministère de l'Education Nationale, de la Recherche et de la Technologie, the Centre National de la Recherche Scientifique, and the Agence Nationale de la Recherche (HELPHOS, ANR-15-CE29-0012-03) for financial support. G.M. aknowledges the National Institute of Health, Minority Biomedical Research Support (grant 1 SC3 GM08958908) and the Henry Dreyfus Teacher-Scholar Award.

Keywords: phosphahelicenes • circular dichroism • luminescence $\cdot$ OLED $\cdot$ quantum-chemical calculations

\section{Notes and references}

[1] Selected reviews: a) Y. Shen, C.-F. Chen, Chem. Rev. 2012, 112, 14631535; b) M. Gingras, Chem. Soc. Rev. 2013, 42, 1051-1095; c) J. Bosson, J. Gouin, J. Lacour, Chem. Soc. Rev. 2014, 43, 2824-2840; d) N. Saleh, C. Shen, J. Crassous, Chem. Sci. 2014, 5, 3680-3694; e) C.-F. Chen, Y. Shen, Helicene Chemistry. From Synthesis to Applications, Springer, 2017.

[2] a) S. Sahasithiwat, T. Mophuang, L. Menbangpung, S. Kamtonwong, T. Sooksimuang, Synth. Met. 2010, 160, 1148-1152; b) L. Shi, Z. Liu, G. Dong, L. Duan, Y. Qiu, J. Jia, W. Guo, D. Zhao, D. Cui, X. Tao, Chem. Eur. J. 2012, 18, 8092-8099; c) W. Hua, Z. Liu, L. Duan, G. Dong, Y. Qiu, B. Zhang, D. Cui, X. Tao, N. Cheng, Y. Liu, RSC Adv. 2015, 5, 7584; d) H. Sakai, S. Shinto, J. Kumar, Y. Araki, T. Sakanoue, T. Takenobu, T. Wada, T. Kawai, T. Hasobe, J. Phys. Chem. C 2015, 119, 13937-13947; e) H. Sakai, T. Kubota, J. Yuasa, Y. Araki, T. Sakanoue, T. Takenobu, T. Wada, T. Kawai, T. Hasobe, J. Phys. Chem. C 2016, 120, 7860-7869; f) Y. Yang, R. Correa da Costa, M. J. Fuchter, A. J. Campbell, Nature Photon. 2013, 7, 634-638; g) Y. Yang, R. Correa da Costa, D.-M. Smilgies, A. J. Campbell, M. J. Fuchter, Adv. Mater. 2013, 25, 2624-2628; h) J. R. Brandt, X. Wang, Y. Yang, A. J. Campbell, M. J. Fuchter, J. Am. Chem. Soc. 2016, 138, 9743-9746. 
[3] a) M. Sapir, E. Vander Donckt, E. Chem. Phys. Lett. 1975, 36, 108-110; b) N. I. Nijegorodov, W. S. Downey, J. Phys. Chem. 1994, 98, 56395643; c) D. Beljonne, Z. Shuai, G. Pourtois, J. L. Bredas, J. Phys. Chem. A 2001, 105, 3899-3907.

[4] a) K. Goto, R. Yamaguchi, S. Hiroto, H. Ueno, T. Kawai, H. Shinokubo, Angew. Chem. Int. Ed. 2012, 51, 10333-10336; b) M. Li, Y. Niu, X. Zhu, Q. Peng, H.-Y. Lu, A. Xia, C.-F. Chen, Chem. Commun. 2014, 50, 29932995; c) H. Oyama, K. Nakano, T. Harada, R. Kuroda, M. Naito, K. Nobusawa, K. Nozaki, Org. Lett. 2013, 15, 2104-2107; d) H. Hirai, K. Nakajima, S. Nakatsuka, K. Shiren, J. Ni, S. Nomura, T. Ikuta, T. Hatakeyama, Angew. Chem. Int. Ed. 2015, 54, 13581-13585; e) C. Shen, M. Srebro-Hooper, M. Jean, N. Vanthuyne, L. Toupet, J. A. G. Williams, A. R. Torres, A. J. Riives, G. Muller, J. Autschbach, J. Crassous, Chem. Eur. J. 2017, 23, 407-418

[5] Selected references: a) C. Fave, T. Y. Cho, M. Hissler, C. W. Chen, T. Y. Luh, C. C. Wu, R. Réau, J. Am. Chem. Soc. 2003, 125, 9254-9255; b) H. C. Su, O. Fadhel, C. J. Yang, T. Y. Cho, C. Fave, M. Hissler, C. C. Wu, R. Réau, J. Am. Chem. Soc. 2006, 128, 983-995; c) O. Fadhel, M. Gras, N. Lemaitre, V. Deborde, M. Hissler, B. Geffroy, R. Réau, Adv. Mater. 2009, 21, 1261-1265; d) P.-A. Bouit, A. Escande, R. Szucs, D. Szieberth, C. Lescop, L. Nyulaszi, M. Hissler, R. Réau, J. Am. Chem. Soc. 2012, 134, 6524-6527; e) F. Riobé, R. Szucs, P. A. Bouit, D. Tondelier, B. Geffroy, F. Aparicio, J. Buendia, L. Sanchez, R. Réau, L. Nyulaszi, M. Hissler, Chem. Eur. J. 2015, 21, 6547-6556; f) H. Chen, W. Delaunay, L. Yu, D. Joly, Z. Wang, J. Li, Z. Wang, C. Lescop, D. Tondelier, B. Geffroy, Z. Duan, M. Hissler, F. Mathey, R. Réau, Angew. Chem. Int. Ed. 2012, 51, 214-217.

[6] See reviews: a) R. Réau, T. Baumgartner, Chem. Rev. 2006, 106, 46814727; b) D. Joly, P. A. Bouit, M. Hissler, J. Mater. Chem. C 2016, 4, 3686-3698; c) M. P. Duffy, W. Delaunay, P. A. Bouit, M. Hissler, Chem. Soc. Rev. 2016, 45, 5296-5310.

[7] a) K. Yavari, S. Moussa, B. Ben Hassine, P. Retailleau, A. Voituriez, A. Marinetti, Angew. Chem. Int. Ed. 2012, 51, 6748-6752; b) K. Yavari, P. Retailleau, A. Voituriez, A. Marinetti, Chem. Eur. J. 2013, 19, 99399947; c) P. Aillard, P. Retailleau, A. Voituriez, A. Marinetti, Chem. Comm. 2014, 50, 2199-2201; d) K. Yavari, P. Aillard, Y. Zhang, F. Nuter, P. Retailleau, A. Voituriez, A. Marinetti, Angew. Chem. Int. Ed. 2014, 53, 861-865; e) P. Aillard, A. Voituriez, D. Dova, S. Cauteruccio, E. Licandro, A. Marinetti, Chem. Eur. J. 2014, 20, 12373-12376; f) P. Aillard, P. Retailleau, A. Voituriez, A. Marinetti, Chem. Eur. J. 2015, 21, 1198911993; g) M. Gicquel, Y. Zhang, P. Aillard, A. Voituriez, A. Marinetti, Angew. Chem. Int. Ed. 2015, 54, 5470-5473; [h] P. Aillard, M. Gicquel, K. Yavari, P. Retailleau, A. Voituriez, A. Marinetti, Eur. J. Org. Chem. 2018, 5853-5860.

[8] a) N. Fukawa, T. Osaka, K. Noguchi, K. Tanaka, Org. Lett. 2010, 12, 1324-1327; b) K. Nakano, H. Oyama, Y. Nishimura, S. Nakasako, K. Nozaki, Angew. Chem. Int. Ed. 2012, 51, 695-699; c) Y. Sawada, S. Furumi, A. Takai, M. Takeuchi, K. Noguchi, K. Tanaka, J. Am. Chem. Soc. 2012, 134, 4080-4083; d) S. Nishigaki, K. Murayama, Y. Shibata, K. Tanaka, Mater. Chem. Front. 2018, 2, 585-590. For helicenes containing 6-membered phosphorus rings, see: e) S. Hashimoto, S. Nakatsuka, M. Nakamura, T. Hatakeyama, Angew. Chem. Int. Ed. 2014, 53, 1407414076.

[9] See reviews: a) M. J. Narcis, N. Takenaka, Eur. J. Org. Chem. 2014, 21 34; b) P. Aillard, A. Voituriez, A. Marinetti, Dalton Trans. 2014, 43, 15263-15278.

[10] Selected examples of CPL active helicenes: a) J. E. Field, G. Muller, J. P. Riehl, D. Venkataraman, J. Am. Chem. Soc. 2003, 125, 1180811809; b) Y. Sawada, S. Furumi, A. Takai, M. Takeuchi, K. Noguchi, K. Tanaka, J. Am. Chem. Soc. 2012, 134, 4080-4083; c) K. E. S. Phillips, T. J. Katz, S. Jockusch, A. J. Lovinger, N. J. Turro, J. Am. Chem. Soc. 2001, 123, 11899-11907; d) T. Kaseyama, S. Furumi, X. Zhang, K. Tanaka, M. Takeuchi, Angew. Chem. Int. Ed. 2011, 50, 3684-3687; e) K. Nakamura, S. Furumi, M. Takeuchi, T. Shibuya, K. Tanaka, J. Am. Chem. Soc. 2014, 136, 5555- 5558; f) C. Shen, E. Anger, M. Srebro, N. Vanthuyne, K. K. Deol, T. D. Jefferson Jr., G. Muller, J. A. G. Williams, L. Toupet, C. Roussel, J. Autschbach, R. Réau, J. Crassous, Chem. Sci. 2014, 5, 1915-1927; g) N. Saleh, M. Srebro, T. Reynaldo, N. Vanthuyne, L. Toupet, V. Y. Chang, G. Muller, J. A. G. Williams, C. Roussel, J. Autschbach, J. Crassous, Chem. Comm. 2015, 51, 3754-3757; h) N. Saleh, B. Moore, II, M. Srebro, N. Vanthuyne, L. Toupet, J. A. G. Williams, C. Roussel, K. K. Deol, G. Muller, J. Autschbach, J. Crassous, Chem. Eur. J. 2015, 21, 1673-1681; i) I. Hernandez Delgado, S. Pascal, A. Wallabregue, R. Duwald, C. Besnard, L. Guénée, C. Nançoz, E. Vauthey, R. C. Tovar, J. L. Lunkley, G. Muller, J. Lacour, Chem. Sci. 2016, 7, 4685-4693; j) T. Katayama, S. Nakatsuka, H. Hirai, N. Yasuda, J. Kumar, T. Kawai, T. Hatakeyama, J. Am. Chem. Soc. 2016, 138, 5210-5213; k) S. Abbate, G. Longhi, F. Lebon, E. Castiglioni, S. Superchi, L. Pisani, F. Fontana, F. Torricelli, T. Caronna, C. Villani, R. Sabia, M. Tommasini, A. Lucotti, D. Mendola, A. Mele, D. A. Lightner, J. Phys. Chem. C 2014, 118, 1682-1695; I) N. Hellou, M. Srebro-Hooper, L. Favereau, F. Zinna, E. Caytan, L. Toupet, V. Dorcet, M. Jean, N. Vanthuyne, J. A. G. Williams, L. Di Bari, J. Autschbach, J. Crassous, Angew. Chem. Int. Ed. 2017, 56, 8236-8239.

[11] a) J. Autschbach, Chirality 2009, 21, E116-E152; b) M. Srebro-Hooper, J. Autschbach, J. Autschbach, Annu. Rev. Phys. Chem. 2017, 68, 399420.

[12] a) J. Autschbach, M. Srebro, Acc. Chem. Res. 2014, 47, 2592-2602; b) M. Srebro, J. Autschbach, J. Chem. Theory Comput. 2012, 8, 245-256.

[13] a) M. Srebro, N. Govind, W. A. de Jong, J. Autschbach, J. Phys. Chem. A 2011, 115, 10930-10949; b) M. El Sayed Moussa, M. Srebro, E. Anger, N. Vanthuyne, C. Roussel, C. Lescop, J. Autschbach, J. Crassous, Chirality 2013, 25, 455-465; c) D.H. Friese, C. Hättig, Phys. Chem. Chem. Phys. 2014, 16, 5942-5951.

[14] See reviews: a) H. Maeda, Y. Bando, Pure Appl. Chem. 2013, 85, $1967-$ 1978; b) E. M. Sanchez-Carnerero, A. R. Agarrabeitia, F. Moreno, B. L. Maroto, G. Muller, M. J. Ortiz, S. de la Moya, Chem. Eur. J. 2015, 21 , 13488-13500; c) J. Kumar, T. Nakashima, T. Kawai, J. Phys. Chem. Lett. 2015, 6, 3445-3452. 
Entry for the Table of Contents (Please choose one layout)

Layout 2:

\section{FULL PAPER}

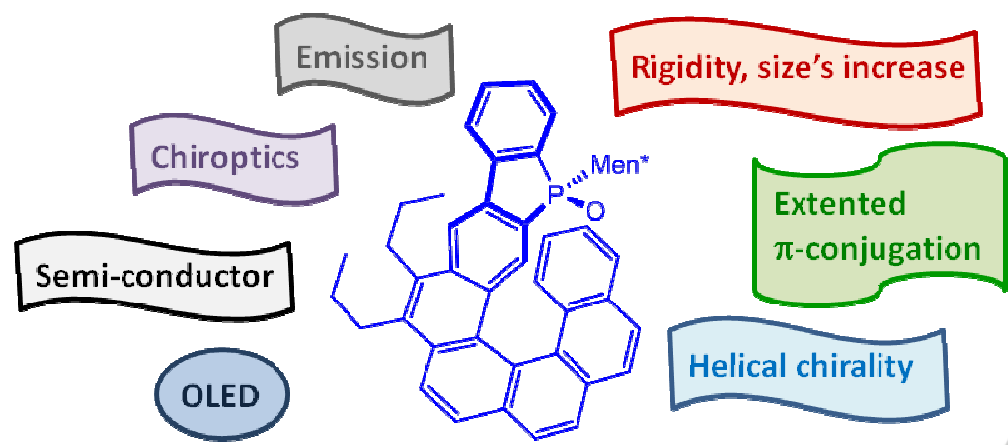

Keihann Yavari, ${ }^{[b]}$ Wylliam Delaunay, ${ }^{[a]}$ Nicolas De Rycke, ${ }^{[a, c]}$ Thibault Reynaldo, ${ }^{[a]}$ Paul Aillard, ${ }^{[b]}$ Monika Srebro-Hooper, ${ }^{*[d]}$ Victoria Y. Chang, ${ }^{[e]}$ Gilles Muller, ${ }^{[e]}$ Denis Tondelier, ${ }^{[f]}$ Bernard Geffroy, ${ }^{[f]}$ Arnaud Voituriez, ${ }^{*[b]}$ Angela Marinetti, ${ }^{\star[b]}$ Muriel Hissler, ${ }^{,[a]}$ and Jeanne Crassous ${ }^{\star[a]}$

\section{Page No. - Page No.}

Phosphahelicenes: from chiroptical and photophysical properties to OLED applications 
